\title{
Further short range endemic troglobitic silverfish (Zygentoma: Nicoletiidae; Subnicoletiinae and Coletiniinae) from north-western Australia
}

\author{
Graeme B. Smith ${ }^{1 *}$ and Jane McRae ${ }^{2}$ \\ ${ }^{1}$ Australian Museum, 1 William St, Sydney, New South Wales 2010, Australia. \\ 2 Bennelongia Pty Ltd, 5 Bishop St, Jolimont Western Australia 6014, Australia. \\ * Corresponding author: le_gbsmith@optusnet.com.au
}

\begin{abstract}
Two new species of silverfish are described from deep subterranean habitat of northwestern Australia. One belongs to Lepidospora (Brinckina) Wygodzinsky and is the first record of the subfamily Coletiniinae in Australia. The second species belongs to the genus Metrinura Mendes, and is the first to be described from Western Australia.
\end{abstract}

KEYWORDS: Thysanura, hypogean, troglobite, new species, key

urn:Isid:zoobank.org:pub:15CCC168-B836-47EA-88FD-19FA5669A1F1

\section{INTRODUCTION}

Silverfish of the family Nicoletiidae are eyeless and lack pigment. They are found in soil-related or subterranean habitats such as caves. Smith (1998) reviewed the family in Australia, at that time treating the Atelurinae as a separate family, rather than as a subfamily of the Nicoletiidae. More recent publications (Smith et al., 2012, Smith \& McRae, 2014 and Smith, 2016) have shown the deep subterranean habitats in Western Australia's Pilbara region to have a diverse nicoletiid silverfish fauna including also genera of the Atelurinae usually considered as inquilines of ants or termites rather than hypogean. When describing some subterranean Atelurinae Smith \& McRae (2014) noted that species of Hemitrinemura Mendes, 1994 had also been collected from the same drill holes. Subsequent closer examination of this material has found that these specimens in fact belong to Lepidospora (Brinckina) Wygodzinsky, 1955 of the subfamily Coletiniinae. This subfamily had not previously been reported from Australia, with most of its species described from the Afrotropical, Palaearctic and Indo-Malaya zoogeographic regions. One new species of this subgenus is described along with a new species of Metrinura Mendes, 1994, a genus of the Subnicoletiinae with several representatives already described from Australia, but the first to be described from Western Australia and also the first from the deep subterranean habitat.

\section{SPECIMEN COLLECTION AND PREPARATION METHODS}

Specimens were collected from mining exploration drill holes using the methodology outlined in Halse \& Pearson (2014) and stored in 100\% ethanol. Silverfish are quite soft bodied and easily damaged during collection from deep subterranean habitats. They are also often covered with very fine dust which can obscure observations.

A series of measurements of all specimens was undertaken according to the method described in Smith (2013). All silverfish specimens mentioned will be deposited with the Western Australian Museum, Perth. Unless specified as being mounted on slides, all specimens are stored individually in 80 or $100 \%$ ethanol.

Some specimens, including always the holotype, were dissected in 80\% ethanol using an Olympus SZ61 stereomicroscope and each mounted on two or three slides using Tendeiro medium (Molero-Baltanás et al., 2000), with the head and thorax mounted on one slide and the abdomen on a second slide. Drawings made with the aid of an Olympus CX31 binocular microscope fitted with a U-DA drawing attachment. Tissue samples were collected during dissection for possible sequencing at a later date. Some twisting of macrochaetae was observed, but this was not as extensive as previously reported (Smith et al., 2012) when specimens were dissected in $100 \%$ ethanol. 
Roman numerals are used to indicate abdominal segment number. The following abbreviations are also used: HW: head width (in millimetres); $\mathrm{H}+\mathrm{B}$ : head and body length (in millimetres); L/W: length to width (ratio); PI, PII, PIII: legs of pro-, meso- and metathorax respectively. The term macrochaetae refers to the larger stronger bristles, setae refers to smaller thinner bristles (usually simple) and setulae to the very small microsetae. Terminology for the 'segments' of the antennae, terminal filaments and ovipositor follows that explained in Smith (2015) where the term annulus will be used for each single unit of the flagellum (excluding pedicel and scape), usually a widened region carrying a single rosette of setae (but occasionally with a smaller secondary rosette), T-annulus for each annulus bearing a trichobothrium, interval for the group of annuli between T-annuli with the T-annulus being the most distal annulus of the interval. For the terminal filaments and ovipositor, the term division will be used for each 'segment' defined by a visible suture, albeit often faint.

\section{SYSTEMATICS}

\section{Family Nicoletiidae Lubbock, 1873}

Nicoletiadae Lubbock, 1873: 201.

Gymnodermata Joseph, 1882: 25.

Nicoletiinae Lubbock._Escherich, 1905: 36.

Nicoletiidae Lubbock.--Remington, 1954: 284.

\section{Subfamily Coletiniinae Mendes 1988}

Coletiniinae Mendes, 1988: 768.

\section{Lepidospora (Brinckina) Wygodzinsky 1955}

Lepidospora Escherich, 1905: 131 pro parte.

Lepidospora (Brinckina) Wygodzinsky, 1955: 179.

\section{TYPE SPECIES}

Lepidospora (Brinckina) makapaan Wygodzinsky, 1955 by original designation.

\section{Lepidospora (Brinckina) relicta sp. nov.}

Figures 1-34

urn:Isid:zoobank.org:act:18AFB41F-87DD-4A6E-B432C78C3962DDFF

\section{MATERIAL EXAMINED}

\section{Holotype}

Australia: Western Australia: $\widehat{\partial}$ (HW 0.75), Cape Preston, Central block (A18 shallow CPM040) $\left(21.07758^{\circ} \mathrm{S}, 116.1465^{\circ} \mathrm{E}\right), 27$ September 2007, J.S. Cocking, M.D. Scanlon, scrape method to $33 \mathrm{~m}$ depth (WAM E89239) on three slides, pieces of terminal filaments and an antenna plus one leg were found in the same tube as the holotype, presumably from it, and were mounted on a separate slide.

\section{Paratypes}

Australia: Western Australia: $\hat{\jmath}$ (HW 0.70), Cape Preston, Central block (A34 CPM 009) $\left(21.0713^{\circ} \mathrm{S}\right.$, $\left.116.14119^{\circ} \mathrm{E}\right), 11$ February 2008, J.S. Cocking, M.D. Scanlon, scrape method (WAM E89240) on two slides including a piece of one antennae and five pieces of terminal filament that were loose in the same tube and presumably from this and the following specimen; ô (HW 0.70), same data as previous (WAM E89241) incomplete specimen in two pieces (head, thorax and abdomen I+II, and abdomen III-VI) in alcohol; $q$ (HW 0.78), Cape Preston, Central block (A6 CPM011)

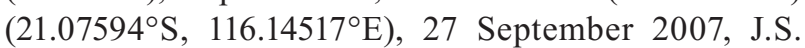
Cocking, M.D. Scanlon, scrape method to $35 \mathrm{~m}$ depth (WAM E89244) in $100 \%$ ethanol in two pieces in poor condition covered with fine fungal hyphae.

\section{DIAGNOSIS}

Males of this species can be distinguished from other species of the subgenus by a combination of characters such as the shape of the apophysis and its terminal spine, the absence of longer setae over the disc of the tergites, the lack of chaetotaxy in the medial region of the posterior margin of the tergites including urotergite IX, the elongated and downward directed posterior processes of urotergite $\mathrm{X}$ and its $10+10$ pegs, the barbed styli, the slightly protruding posterior margin of urosternite VIII which is straight not round, the very thin curved parameres and by the presence of $2+2$ conules on both of the first two divisions of the median filament.

\section{DESCRIPTION}

Appearance: Medium sized, parallel-sided silverfish with elongate antennae and terminal filaments i.e. a shape typical for genus (Figure 1). Appearance when live unknown, probably white in colour, alcohol preserved specimens off-white. Pigment lacking.

Body length: $\mathrm{H}+\mathrm{B}$ in preserved specimens examined, up to about $6.5 \mathrm{~mm}$ (HW 0.75) after accounting for the distended abdomen, thorax length up to $1.93 \mathrm{~mm}$ or about one quarter $\mathrm{H}+\mathrm{B}$ and width $0.93 \mathrm{~mm}$; antennae broken in all specimens but at least two thirds $\mathrm{H}+\mathrm{B}$; caudal filaments broken in all specimens, estimating from loose pieces in tube their length is probably as long as $\mathrm{H}+\mathrm{B}$.

Scales: Multi-radiate with about 15-20 ribs which do not extend significantly beyond the posterior end of the membranes, similar in shape on both dorsal (Figure 2) and ventral surfaces (Figure 3), mostly rounded or somewhat pointed apically, those on the ventral surface somewhat larger; scales covering body but absent from head and its appendages, from the legs (although present on all coxae), paramera, cerci and median dorsal appendage and probably the ovipositor (present on subgenital plate). 
Macrochaetae: Most simple, parallel-sided with distinct apical bifurcations (Figure 4) but some on legs are stout and carrot-shaped usually without an apical bifurcation. Some of the longer parallel-sided macrochaetae, when slide mounted, show the same distortion reported in Smith et al. (2012) which is now believed to be an artefact caused by the Tendeiro medium.

Head: Almost as long as wide, not covered by prothorax at hind margin (Figures 5 and 6), prognathous, vertex with $1+1$ long macrochaetae in postero-lateral corners each accompanied by a small macrochaeta laterad to them; $3+3$ long macrochaetae in antero-lateral corners adjacent to the antennal bases and $1+1$ setae between the two groups; disc with scattered small fine setae. Clypeus with transverse row of six setae, the outermost being apically bifurcate. Labrum with similar transverse row of setae, two of which are longer than the others (Figure 5). Antennae elongate; scape of $\widehat{\lambda}$ long, with several strong macrochaetae (Figure 6); pedicel of $\hat{\sigma}$ with large thumb-shaped apophyses on mediad face (Figures 6-8) about three times longer than wide, armed sub-apically with a short conical seta on the dorsal aspect, each apophysis reaching to about half the length of the apparently long first interval of the flagellum; this first interval appears to be one complete interval on both antennae of the holotype but on the paratype (E89240) weak sutures are visible indicating the basal interval is composed of four annuli; six trichobothria on the basal annulus and two each on the following three annuli; the next interval (nominally the fifth interval) has two rosettes of setae each with two trichobothria, intervals six to eight also with two rosettes of setae but with two trichobothria only in the most distal rosette; subsequent intervals further subdivided into four annuli, each with a rosette of setae and two trichobothria in the most distal annulus; intervals on more distal fragment consisting of eight annuli and apparently only a single trichobothrium in the most distal annulus. Mandibles (Figures 9, 10) strong with well-developed molar and incisor regions and one apically bifurcate macrochaeta on the external face as well as a few longer simple setae. Maxillae (Figures 11-12) of usual form, galea only surpassing length of lacinia by the two distinct apical papillae, lacinia well sclerotized with one strong apical tooth and a quite strong secondary tooth; pectinate prostheca shorter than lacinia with several rounded lamellae and about 12 setae along margin; maxillary palp very long with the ultimate article about five times longer than wide and 1.0-1.2 times longer than the penultimate article, second article with subapical ring of strong apically bifurcate setae, third article subapically with one stronger seta, ultimate article with six papillae of usual form. Labium (Figure 13) longer than wide with palp quite short compared to that of the maxilla, ultimate article is about 1.4 times longer than wide (range 1.32-1.50) with six papillae of usual type; the penultimate article with a rosette of longer stronger setae in proximal third.
Thorax: Weak, about one quarter $\mathrm{H}+\mathrm{B}$ and not wider than the abdomen, all nota of similar size; prothorax with obvious collar of longer and shorter macrochaetae and smaller setae, all nota with several strong apically bifurcate macrochaetae near but not on the lateral and the outer parts of the posterior margins, as well as shorter setae and setulae, the medial part of the posterior margin without macrochaetae; disc of nota with scattered setulae (Figures 14-16).

Legs typical for genus, tibia L/W ratio of legs PI 3.23.5, PII 4.0-4.1, PIII 4.6-4.9; tarsi L/W ratio PI 9.1-11.2, PII 9.1-10.9, PIII 13.0-14.5. Legs becoming increasingly long from PI to PIII (ratio of tibia length PI to PIII = 0.62 and tarsus $=0.64$ ). Legs quite elongate (Figures 17, 18). Coxae with about five long macrochaetae spaced along the outer margin, with smaller macrochaetae more distally along this margin as illustrated, inner margin also with two macrochaetae, margins and face covered with scattered fine setae and some scales; trochanter with one small macrochaeta and several smaller setae; femur with about five stout curved spines along leading margin, becoming longer distally, posterior margin with two macrochaetae, the more distal is more robust; tibia with two stout macrochaetae near the dorsal margin about one third and two thirds the distance along this margin, ventral margin with four tapered macrochaetae and three or four smaller, stout macrochaetae in a line near the distal margin, the usual distal spur is fairly short and usually with a couple of small subapical teeth distally (Figure 19); tarsus with four articles the basal one being almost as long as the other three together on PIII, each article with paired stout setae along its ventral surface; pretarsus (Figure 20) with two strong claws and a stout medial empodial claw.

Abdomen: Not much narrower than the thorax at its base. All urotergites wrap around the body but without a sharp fold laterally. A suture between the tergite and the paratergites visible on II-VII. Abdominal tergites (Figure 21) with 3-4+3-4 submarginal apically bifurcate macrochaetae on the postero-lateral margins, three mediad of the suture with the paratergite and one laterad of the suture, as well as three or four simple setae almost as long as the macrochaetae but arising closer to the margins and some smaller setulae; medial area of posterior margin glabrous. Urotergite IX (Figure 22) with only $1+1$ bifurcate macrochaetae and $3+3$ long setae (plus setulae) in the postero-lateral corners. Discs of all tergites with a few scattered setulae, decreasing in number posteriorly. Urotergite $\mathrm{X}$ with shallow rounded posterior emargination, the posterior corners appearing rounded from above (Figures 23, 24), but these are actually the side of a downward pointing projection better seen in the paratype (Figure 25) where urotergite $\mathrm{X}$ is lying on its side; each arm of the tergite armed with 10 pegs, lateral margins of each arm with a few stout setae as well as some on the disc near the posterior rounded projections.

Urosternite I divided into a median sternum and two lateral coxites (Figure 26), the sternum with a few setae in the medial region, the posterior margin with a longer 
seta on each coxite near the suture and the sternum with two setae, as well as some setulae. Urotergites II-VII entire (Figure 27), not divided into separate coxites and median sternum, each bearing $1+1$ styli and two strong apically bifurcate macrochaetae in the middle of the disc, and another subposteriorly on each side mediad of the base of each stylus; posterior margin with $1+1$ macrochaetae and some setulae, the margins laterad of the styli with a few setae and setulae. Eversible vesicles (Figure 28), each with about four or five setae on the vesicle as well as a few setulae, on urosternites II-VI; VII with pseudovesicles. Urosternite VIII (Figure 29) entire, without vesicles, with $1+1$ subposterior macrochaetae as well as the $1+1$ macrochaetae mediad of each stylus base but lacking macrochaetae on the disc of the sternite, posterior margin slightly protruding and with some setulae, margins laterad of the styli with two setae and some setulae. Apical spine of the few styli still present all with three teeth (Figure 30).

Urosternite IX (Figure 31) divided into separate coxites bearing styli and long, slightly curved parameres (L/W 7.3-9.8). Parameres reach to about one half or two thirds the length of the styli, with several setae along their length and some small apical setulae. External process with one small seta and a setula; internal process with setae near the inner margin. Penis in holotype partly obscured by dirt, with longitudinal opening lined with hairs or lamellae, some glands visible basally.

Appendix dorsalis of $\hat{\delta}$ dorsally with $2+2$ pegs on each of the two basal divisions (Figure 23), following division with two rosettes of setae, macrochaetae and small trichobothria, the ventral macrochaetae strongly bifurcate; more distal divisions also with two rosettes of setae and macrochaetae, with those on the ventral face strongly bifurcate (two macrochaetae in the proximal rosette and three in the distal), trichobothria on the distal rosette of every fourth division (Figure 32); basal division of cerci (Figure 23) without modified chaetotaxy, following division with two rosettes of setae and trichobothria, each rosette with a modified peg on the medial face, third division (lacking obvious suture with second division on the left cercus of the holotype) similar to second, fourth division without modified chaetotaxy, having two rosettes of setae, macrochaetae and trichobothria; more distal divisions very long with several rosettes per division, the divisions possibly subdivided by indistinct sutures (Figure 33).

\section{Female}

As for male except pedicel without apophyses; urotergite $\mathrm{X}$ trapezoidal with $1+1$ macrochaetae in the postero-lateral corners plus a mediad seta, medial indentation shallow (Figure 34), without pegs on ventral surface; terminal filaments presumably also without pegs. Genital region damaged and not easy to examine. Subgenital plate rounded subtriangular with small submarginal setae distally. Ovipositor is very slightly spindle-shaped (wider in the mid region) and not particularly long, probably only reaching to about the apices of styli IX (if they had not been lost), with about 14 divisions. The apex of the anterior valves with a typical acute triangular projection, that of the posterior valves rounded; both with simple fine setae only.

\section{ETYMOLOGY}

The species is named from the Latin adjective relicta meaning relic, assuming the new species represents one of the last remnants of a once more widely distributed genus.

\section{HABITAT}

All material examined was collected from boreholes in outcrops of weathered banded iron formation containing vugs and voids that provide habitat for troglofauna. Mean annual rainfall at nearby Mardie weather station is $277 \mathrm{~mm}$, with $88 \%$ of the rain falling between January and June. The mean annual maximum temperature is $33.9^{\circ} \mathrm{C}$, with mean monthly maximum temperatures being close to $38^{\circ} \mathrm{C}$ from January to March.

\section{DISCUSSION}

This species is the first of the subfamily Coletiniinae to be described from Australia; all other nicoletiids belong to the Subnicoletiinae or Atelurinae. Reexamination of further material collected from deep subterranean habitats in the Pilbara which was previously thought to belong to Hemitrinemura has shown all specimens to belong to Lepidospora (Brinckina), including material from three areas of the Hamersley Range near Mt Farqhar (S22.58 ${ }^{\circ}$ E116.73 $)$, Mt Sheila $\left(\mathrm{S} 22.13^{\circ} \mathrm{E} 117.76^{\circ}\right)$ and Paraburdoo (S23.16 E117.90 ${ }^{\circ}$.

The great majority of Coletiniinae species have been described from the Afrotropical, Palaearctic and IndoMalaya biogeographic regions, with just a single species described from the Neotropical region. The subgenus Brinckina is known from the Democratic Republic of Congo, Kenya, South Africa, China and Afghanistan, but until now not Australia although its presence in Papua New Guinea was suspected (Smith, 1998).

The apparent absence of Coletiniinae records from soil habitats in Australia suggests a similar scenario to that proposed for the Australian Dodecastyla species in Smith \& McRae (2014) where a more widespread genus has survived the increasingly dryer climate in Australia since the mid-Miocene (10-15 MY) by retreating to the more humid deep subterranean habitat. In contrast to Dodecastyla, which has a late Gondwanan distribution (Chile and Australia) c. $50 \mathrm{MY}$, the Coletiniinae have a much broader distribution suggesting a much longer presence in Australia and a possible Pangaean origin (ca 200 MY).

Affinities are difficult to determine based on morphology. This difficulty is only partly due to the quality of earlier descriptions and the possibility of misinterpretation of some characters such as the degree of elongation of urotergite $\mathrm{X}$, but also to the lack of consistent patterns. Two species from the Congo (L. (B.) hamata Mendes, 2002 and L. (B.) garambensis Mendes, 


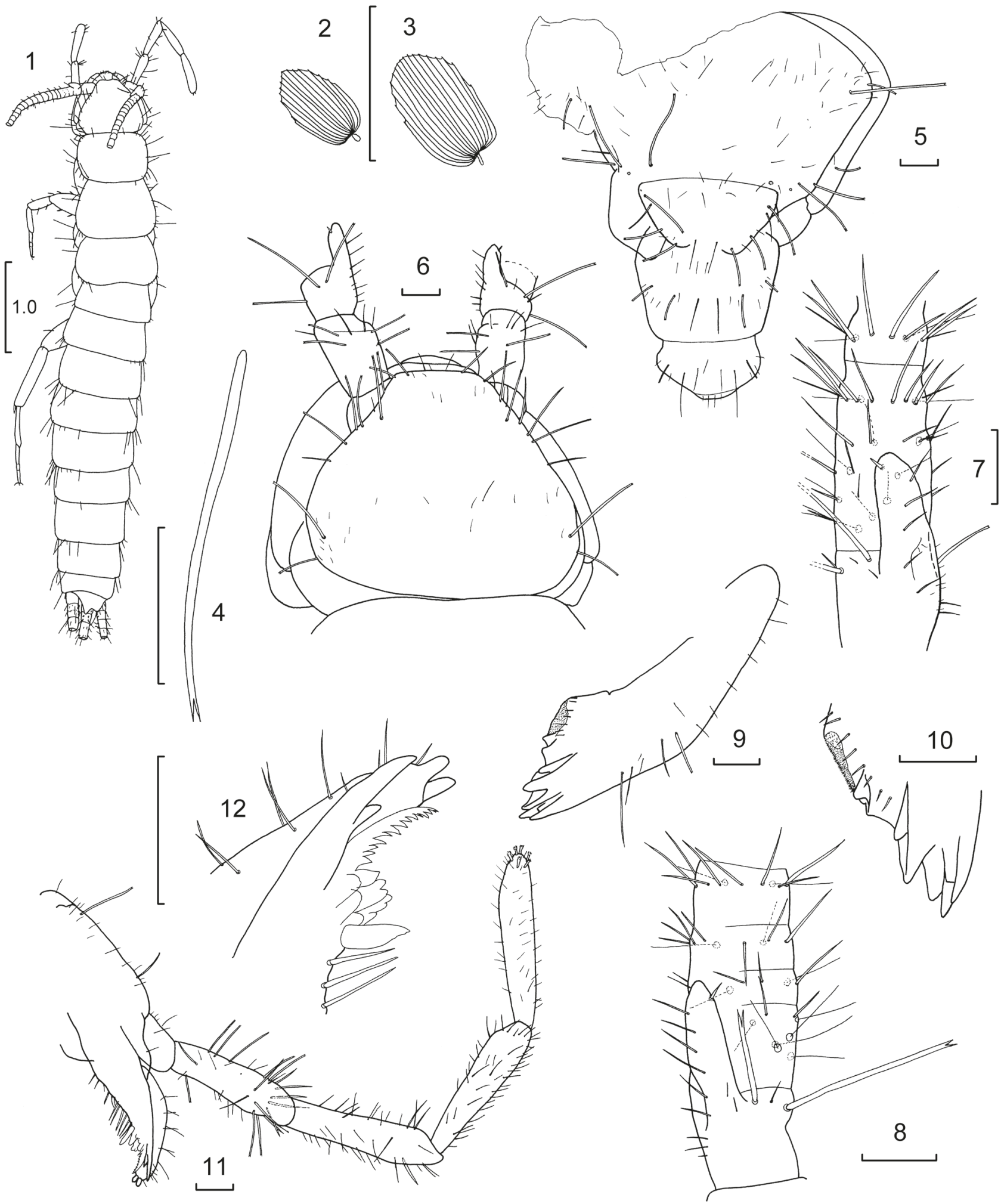

FIGURES 1-12 Lepidospora (Brinckina) relicta sp. nov., holotype $\hat{o}$ unless indicated otherwise by specimen number: 1 , habitus, drawn as if not distended; 2, scale from mesonotum; 3, scale from urosternite; 4, macrochaeta from anterior margin of pronotum; 5, head, on slide; 6, head in alcohol (E89240); 7, left pedicel; 8, right pedicel of $\hat{0}$ paratype (E89240); 9, mandible; 10, idem, molar and incisor areas; 11, maxilla; 12, lacinia, galea and prostheca. All scale bars $0.1 \mathrm{~mm}$ unless otherwise indicated. 


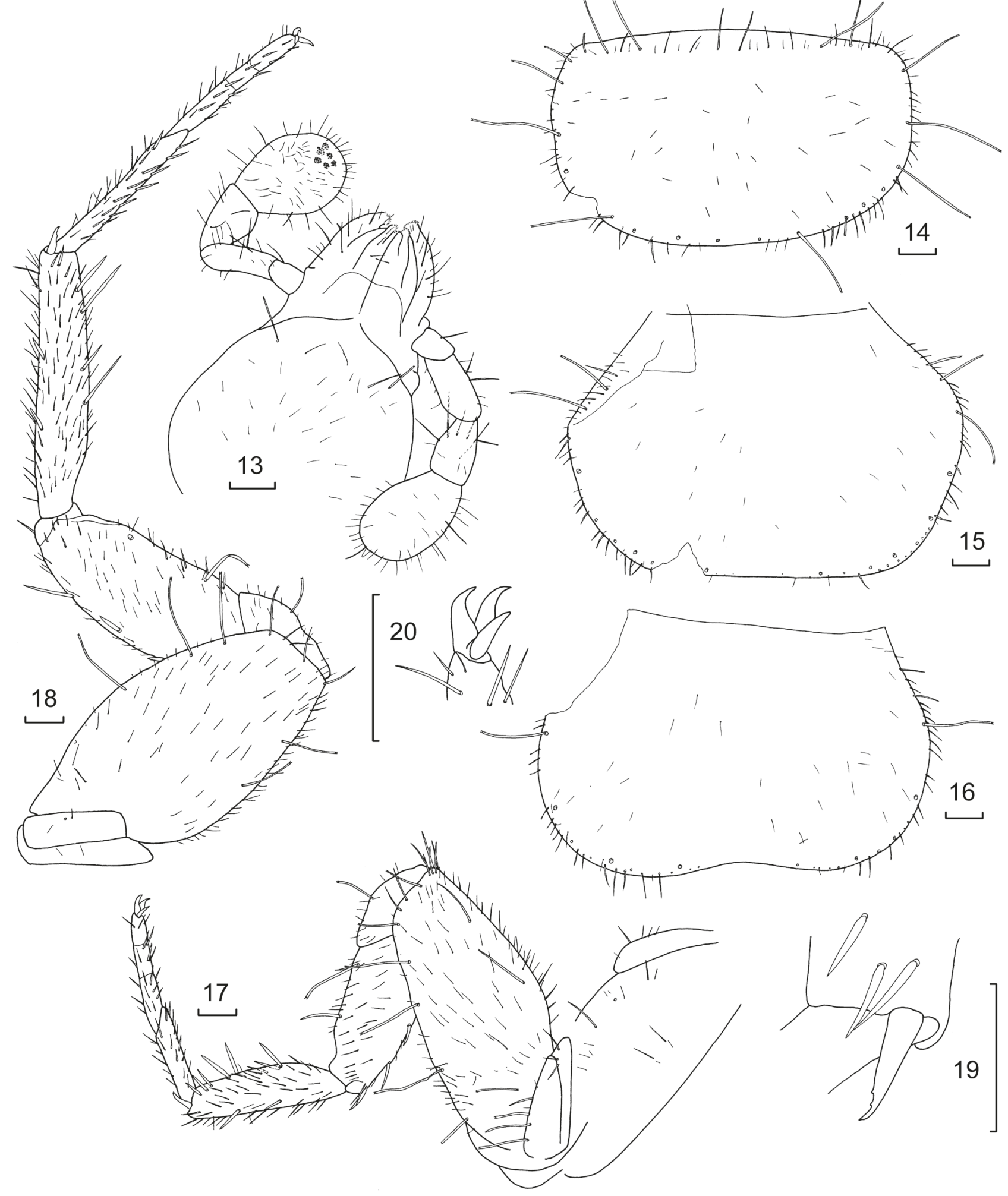

FIGURES 13-20 Lepidospora (Brinckina) relicta sp. nov., holotype ỗ: 13, labium; 14, pronotum; 15, mesonotum; 16, metanotum; 17, PI (WAM E82749); 18, PIII; 19, apex of tibia of PIII; 20, pretarsus of PI. All scale bars $0.1 \mathrm{~mm}$. 


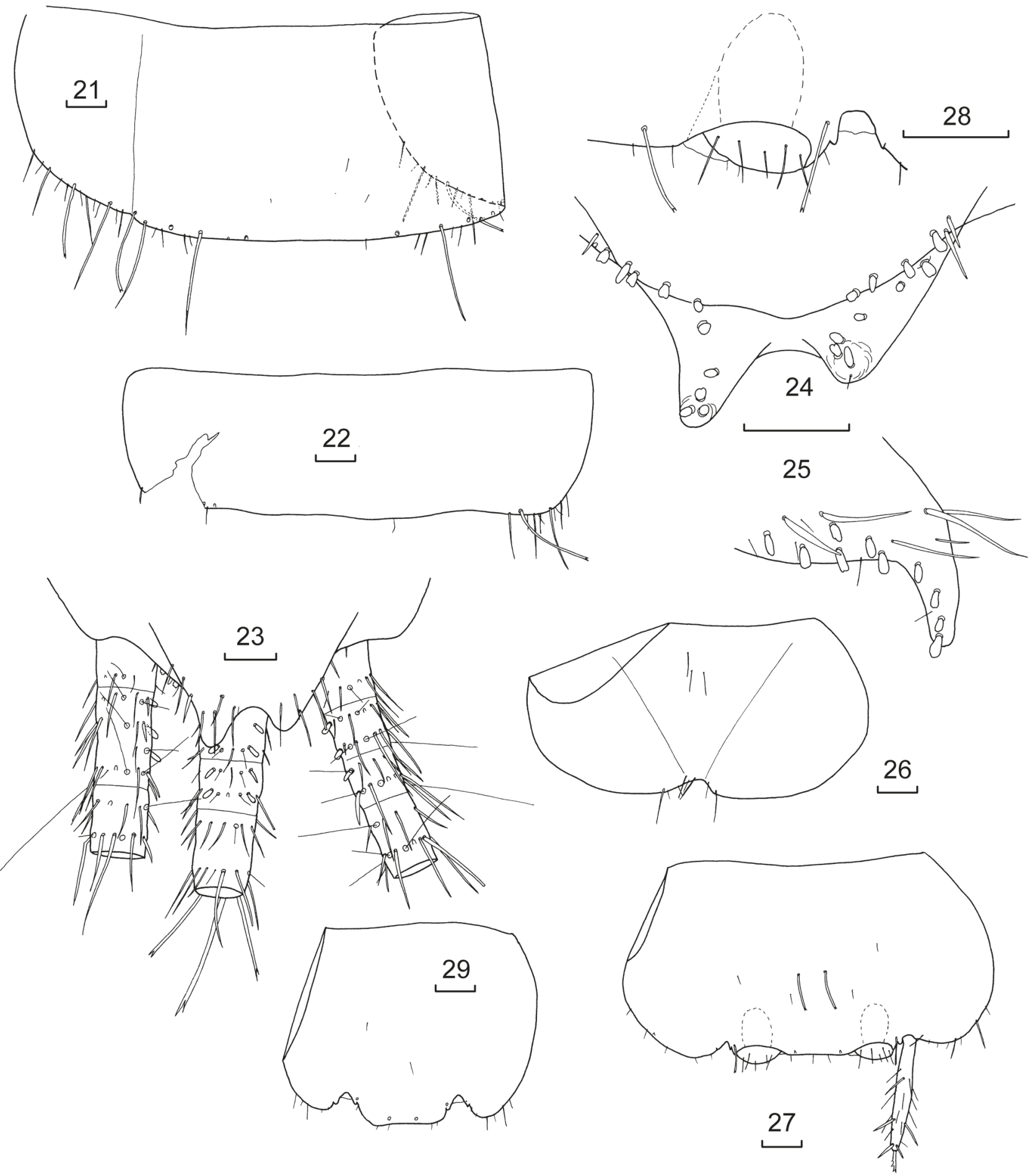

FIGURES 21-29 Lepidospora (Brinckina) relicta sp. nov., holotype $\widehat{\partial}$ unless indicated otherwise by specimen number: 21 , urotergite III; 22, urotergite IX; 23, urotergite X, and base of terminal filaments; 24 , underside of urotergite $X$ of $3 ; 25$, urotergite $X$ of paratype (E89240) ventro-lateral view; 26, urosternite I; 27 , urosternite II; 28 , eversible vesicle of urosternite IV; 29, urosternite IX. All scale bars $0.1 \mathrm{~mm}$. 

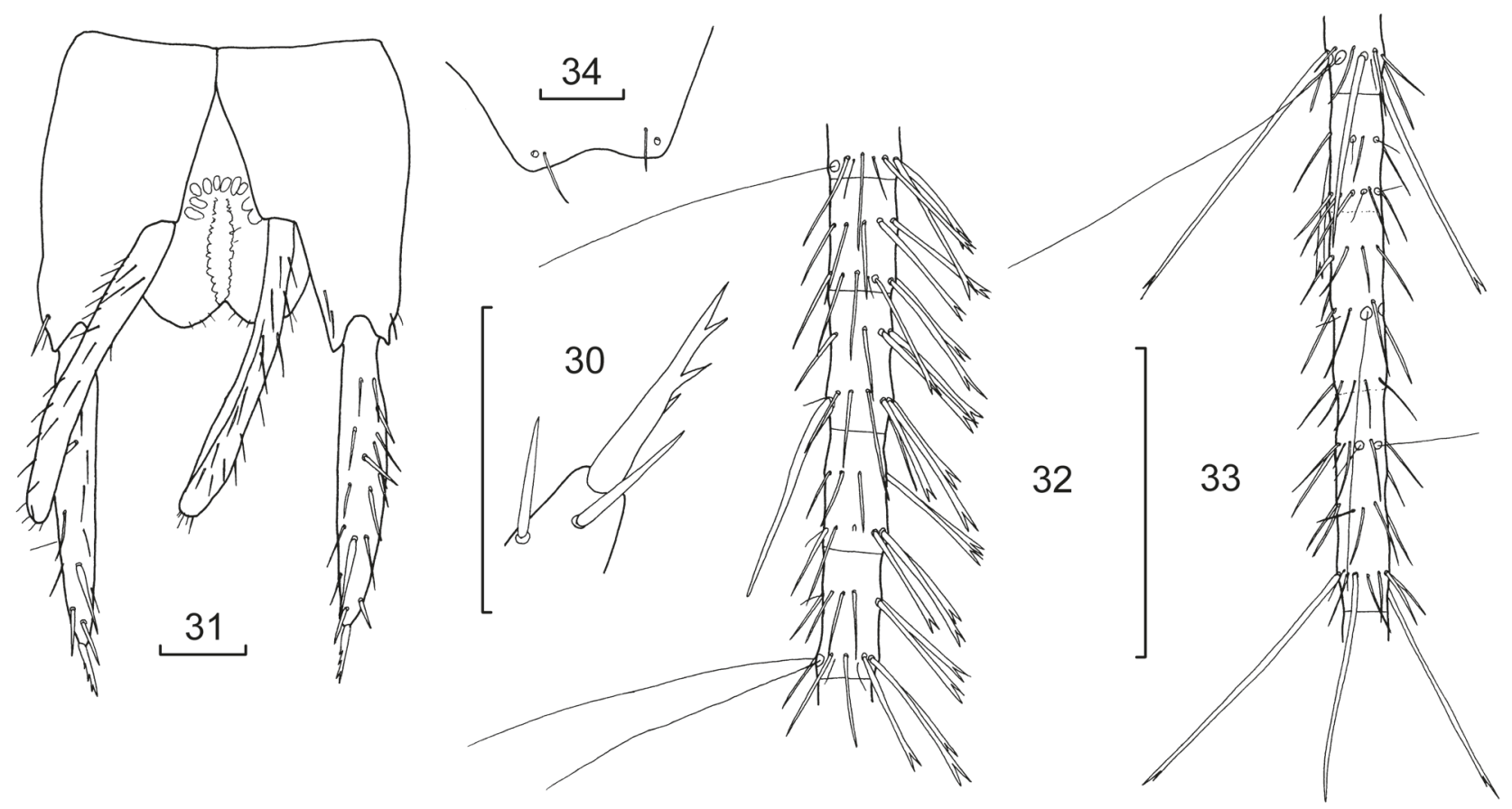

FIGURES 30-34 Lepidospora (Brinckina) relicta sp. nov., holotype male unless indicated otherwise by specimen number: 30 , apex of stylus IX; 31, coxites IX and genital region of $\lambda ; 32$, most distal remaining divisions of appendix dorsalis; 33, most distal remaining divisions of cercus; 34, urotergite X of $q$ (E89244). All scale bars $0.1 \mathrm{~mm}$.

2002) form a reasonably distinct clade as mature males in both species have short pedicellar apophyses with a minute apical spine and they lack modified chaetotaxy on the base of the median filament. All other species (except possibly L. (B.) alticola Wygodzinsky, 1965 where males are not yet known) have a longer thumblike apophysis with a more prominent, and subapical, spine. Completely opposite to the Congo species, Lepidospora. (B.) makapaan Wygodzinsky, 1955 stands alone in having modified chaetotaxy on the median filament but not on the cerci. The new Australian species resembles the Asiatic species (L. (B.) hemitrichoides Wygodzinsky, 1962 from Afghanistan and L. (B.) hemitricha Silvestri, 1942 from Indochina) in having modified chaetotaxy on all terminal filaments in adult males as well as the longer pedicellar apophyses, however the shape of the modified chaetotaxy is quite different with thickened pointed setae in the Asiatic species but rounded pegs in all other species. The Asiatic species also show stronger setation on the disc of all thoracic and abdominal tergites. Lepidospora (B.) relicta also shares with $L$. (B.) hemitrichoides the long extensions to urotergite $\mathrm{X}$, but this character can be difficult to see on some slide mounted material, almost requiring a poorly laid out specimen before it is obvious. The ovipositor, although damaged in the only female specimen available, is short, similar to that of $L$. (B.) makapaan, and in contrast to all other species where it is long. This may be a localised adaptation rather than reflecting phylogeny.
Mendes (2002) presented a key to the Lepidospora. The new species causes problems at couplet 33 as it has an apophyses about three times longer than wide but pegs occur on all terminal filaments. Couplet 33 should be replaced and a new couplet added as follows:

33. Pedicellar apophyses not more than twice as long as wide...... 34

Pedicellar apophyses about three times longer than wide.

37. Pedicellar apophyses somewhat curved, with minute apical spine. Male urotergite $X$ with nonelongated posterior apices bearing (7-9)+(7-9) sclerotised pegs. Paramera about five times longer than wide. Pegs on male cerci only. Ovipositor surpassing end of styli by about 2.5 times the length of the stylus

L. (B.) garambensis Mendes 2002 Eastern Congo, D.R. (E)

Pedicellar apophyses straight, with spine subapical and about $1 / 4$ as long as the apophysis is wide. Male urotergite $\mathrm{X}$ with elongated apices bearing $10+10$ pegs. Paramera seven to ten times longer than wide. Pegs on male cerci and median filament. Ovipositor only about as long as the apices of stylet IX.

L. (B.) relicta sp. nov. Australia (C) 


\section{Subfamily Subnicoletiinae Mendes, 1988}

Subnicoletiinae Mendes, 1988: 769.

\section{Metrinura Mendes, 1994}

Metrinura Mendes, 1994: 99.

\section{TYPE SPECIES}

Trinemura novaecaledoniae Silvestri, 1915 by original designation.

\section{Metrinura taurus sp. nov.}

Figures 35-59

\section{urn:Isid:zoobank.org:act:856AAB06-43B6-49FA-B109- FECC6E0E7F8A}

\section{MATERIAL EXAMINED}

\section{Holotype}

Australia: Western Australia: $\widehat{\jmath}$ (HW 0.78), Kimberley Matsu exploration site c. $100 \mathrm{~km} \mathrm{SSW}$ Kununurra (MATC122 KMG014) (16.70442 ${ }^{\circ} \mathrm{S}$,

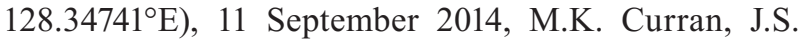
Cocking, scrape method (WAM E89235) on two slides. The holotype was covered in a very fine dust, resulting in some opacity when using the transmission light microscope, however not enough to significantly compromise the description. The holotype was also in a pre-moult condition, with new setae visible under the old cuticle.

\section{Paratypes}

Australia: Western Australia: $\widehat{~}$ (HW 0.81), Kimberley Matsu exploration site, c. $100 \mathrm{~km} \mathrm{SSW}$ Kununurra (MATC001 KMG023) (16.69394으, $\left.128.32834^{\circ} \mathrm{E}\right), 16$ July 2014, M.K. Curran, J.S. Cocking, scrape method (WAM E89236) in alcohol; + (HW 0.94), Kimberley Matsu exploration site, c. $100 \mathrm{~km}$ SSW Kununurra (MATC201 KMG006) (16.70184 S, $\left.128.33634^{\circ} \mathrm{E}\right), 15 \mathrm{July}^{2014}$, M.K. Curran, J.S. Cocking, scrape method (WAM E89237) in alcohol; đ’ (HW 0.85), Kimberley Matsu exploration site (MATC131 KMG016) $\left(\mathrm{S} 16.70549^{\circ} \mathrm{S}, 128.35090^{\circ} \mathrm{E}\right), 15$ July 2014 , M.K. Curran, J.S. Cocking, scrape method (WAM E89238) in alcohol.

\section{DIAGNOSIS}

Mature males of this species can be distinguished from congeners by the unusual horn-shaped apophysis on the pedicel, by the comparatively small proximal and large distal eversible part of the paramera, by the absence of anemone-like structures on the cerci, by the barbs on the apical spine of the styli and the rounded barb on the outer claws of the pretarsus, as well as the short series of stout modified setae on the cerci and appendix dorsalis.

Females can be partially distinguished by the subtriangular shape of the subgenital plate, the shape of the pretarsal claws, the barbs on the apical spine of the styli and the long ovipositor of 13-14 divisions.

\section{DESCRIPTION}

Appearance: Medium sized, parallel-sided silverfish with elongate antennae and terminal filaments (Figure 35 ); appearance when live unknown, probably white in colour, alcohol preserved specimens off-white. Holotype covered in fine dust which adheres differently on different cuticular surfaces.

Head and body lacking scales but covered in scattered hyaline setae, with stronger setae and quite robust, apically bifurcate macrochaetae on the margins. Pigment absent.

Body length: Up to about $8.9 \mathrm{~mm}$ (HW 0.94) in specimens examined but all are somewhat distended (Figure 35) actual length probably around 7-8 $\mathrm{mm}$; thorax length $2.6 \mathrm{~mm}$ or about one third $\mathrm{H}+\mathrm{B}$ and width $1.48 \mathrm{~mm}$; antennae elongate, up to $5.5 \mathrm{~mm}$ or up to 0.62 $\mathrm{H}+\mathrm{B}$; caudal filaments broken in all specimens, up to 2.5 $\mathrm{mm}$ or at least $0.44 \mathrm{H}+\mathrm{B}$ and also probably elongate.

Macrochaetae: Parallel-sided with distinct apical bifurcations (Figure 36) or gradually tapering with simple pointed or apically bifurcate apices.

Head: Wider than long (Figures 37, 38) with several strong macrochaetae along the anterior lateral margins above the antennae as well as stronger macrochaetae in the posterior lateral corners; middle of head covered with scattered smaller setae. Clypeus also with stronger setae. Labrum with transverse row of setae. Antennae elongate; scape of $\hat{\sigma}$ with two weak distal apophyses (Figure 39) and chaetotaxy as illustrated; pedicel of $\hat{\sigma}$ with large prominent apophysis which resembles the horns of a bovine, these appear to be hollow and there are fields of glands visible at their base, with a subdistal ring of long macrochaetae; first interval of flagellum with six trichobothria; the face of each flagellar interval is covered with dust where the intersegmental regions are not; subsequent intervals with two trichobothria; intervals subdivide from the eighth interval into two annuli with the trichobothria in the most distal annulus, further subdividing into four annuli by the $12^{\text {th }}$ or $13^{\text {th }}$ intervals. Most distal intervals divided into eight annuli with just a single trichobothrium in the most distal annulus. Mandibles (Figures 40-41) strong with welldeveloped molar and incisor regions; outer margin with several strong macrochaetae and some smaller setulae. Maxillae (Figures 42-43) of usual form, galea only surpassing length of lacinia by the two distinct apical papillae, lacinia well sclerotized with one strong apical tooth and a quite strong secondary tooth; pectinate prostheca slightly shorter than lacinia with several rounded lamellae (partially obscured by dirt on holotype) and about nine setae along margin; maxillary palp not particularly long with the ultimate article about the same length as the penultimate (range 0.89-1.15) and both articles about four to five times longer than wide, second article with subapical ring of strong setae as well as some equally long but thinner setae in the proximal third; following article with one or two somewhat stronger seta subapically as well as many smaller setae, penultimate article without stronger setae; ultimate article with only 
small setae and four or five apical papillae of usual form. Labium (Figure 44) about as long as wide with a slender but not very long palp; penultimate article quite elongate and armed with long setae in proximal two thirds; ultimate article truncate oval, 1.16 times as long as wide (range 1.08-1.24) with six papillae of usual type.

Thorax: Thorax not much wider than abdomen, about one third $\mathrm{H}+\mathrm{B}$, pronotum (Figure 45) slightly smaller than other nota with obvious strong setal collar behind anterior margin; laterally with about eight strong apically bifurcate macrochaetae spaced along and away from the lateral margins plus some stronger as well as smaller setae on the margins, the submarginal macrochaetae probably becoming smaller towards and along the posterior margins (only sockets remain); disc covered with numerous simple setae. Meso- (Figure 46) and metanotum (Figure 47) similar except for the absence of a setal collar, the insertions difficult to see clearly on the metanotum, appearing to be weaker than on pro- and mesonotum.

Legs very long and thin (Figures 48, 49), tibia L/W ratio of legs PI 3.2 (range 3.1-3.4), PII no data, PIII 4.2 (3.9-4.7); tarsi L/W ratio PI 9.8 (range 7.9-11.1), PII 7.5, PIII 12.0 (8.3-14.80). PIII longer than PI (ratio of tibia length PI to PIII = 0.64 (range $0.55-0.76$ ) and tarsus 0.82 (range 0.71-1.01)). Precoxa of PI with three macrochaetae and several smaller setae. Coxa with about four macrochaetae along outer margin and two long thin macrochaetae near the inner margin as well as smaller setae along both margins and on ventral face. Trochanter without strong setae. Femur with a macrochaeta close to the posterior margin near the trochanter and two macrochaetae on the bulge along this margin, also with one or two stronger setae on the anterior or dorsal margin and smaller setae scattered over the face. Tibia quite slender, possibly with one stout macrochaeta near the dorsal margin, ventral margin with four macrochaetae and two robust setae subdistally, apical spur with distinct barb; tarsus of four articles, the basal being about the same length as the following three together on all legs, armed with small setae, those on the ventral face thicker, especially towards the distal end of each article; pretarsus (Figure 50) of all legs in both sexes with a prominent rounded secondary process on each of the lateral claws, medial empodial claw simple.

Abdomen: Not much narrower than the thorax at its base. All urotergites wrap around the body but without a sharp fold laterally. The disc of all urotergites covered with scattered small setae. A weak suture between the tergite and the paratergites is visible on II-IX. Urotergites I-IX (Figure 51) with several submarginal, apparently simple macrochaetae spaced along the posterior margin, the macrochaetae are larger laterally than medially judging from the size of the insertions. Urotergite $X$ trapezoidal in both sexes (Figures 52, 53) with shallow posterior concave emargination, posterior corners each with two strong macrochaetae and some smaller setae between them as well as some smaller setae along the lateral margins.

Urosternites I-IX entire, not divided into median sternite and lateral coxites, posterior border of urosternites II-VIII almost straight. Urosternite I without styli or exsertile vesicles, with a small seta and a few setulae postero-medially. Urosternite II with vesicles but without styli, with $1+1$ macrochaetae insertions mediad to the vesicles; judging from new macrochaetae forming under the older cuticle, these are short and apically bifurcate. Urosternites III-VI with exsertile vesicles, styli and $1+1$ macrochaetae insertions just mediad of the vesicles plus a few setulae along the margins (Figure 54). Urosternite VII with pseudovesicles, styli and 1+1 macrochaetae insertions. Urosternite VIII with styli and 1+1 macrochaetae insertions only (Figure 55). Urosternite IX (Figure 55) entire, not divided into separate coxites, bearing long styli. Parameres divided into two parts; the basal part reaching only to the base of the styli and with several subapical setae, while the distal part, normally considered to be eversible, is almost as long as the basal part only bearing small setulae apically. It appears to be genuinely long and not everted as the entire surface of both parts of the parameres are covered with the same dust as on the rest of the segment, whereas the urosternite vesicles everted when the animal was put in alcohol are free of the dust seen on the adjacent cuticle. In the paratype (E89236) the parameres are more contracted into the indentation of urosternite IX, the proximal part of the parameres does not reach the base of stylus IX and the distal part, while still quite large, is only about half of that in the holotype, suggesting some degree of eversion in the holotype. Penis in holotype obscured.

Styli on segments III-IX, the apical spine of all styli barbed (Figure 57), three thicker setae along the ventral surface, one about half way along the stylus, another about three quarters along and a smaller one just below the apex.

Cerci and appendix dorsalis of holotype had obviously been lost beyond the third divisions well prior to the collection of the specimen (Figure 58). Quite long, new, thinner terminal appendages had grown from the ends of the remaining divisions and are covered with closely appressed hyaline setae, presumably the incipient replacement terminal appendages extending prior to the encroaching moult. The basal divisions are covered in fine dust and difficult to view but the inner ventral surface of the cerci have stout, pointed spines (modified setae), with one on the first, two on the second and one or two on the third divisions. Basal divisions also with setae and trichobothria. No modified setae were seen on the single surviving division of the appendix dorsalis of the holotype. On the paratype (E89236) six or seven divisions of the terminal filaments are preserved; two modified spines are present on each of the six basal 

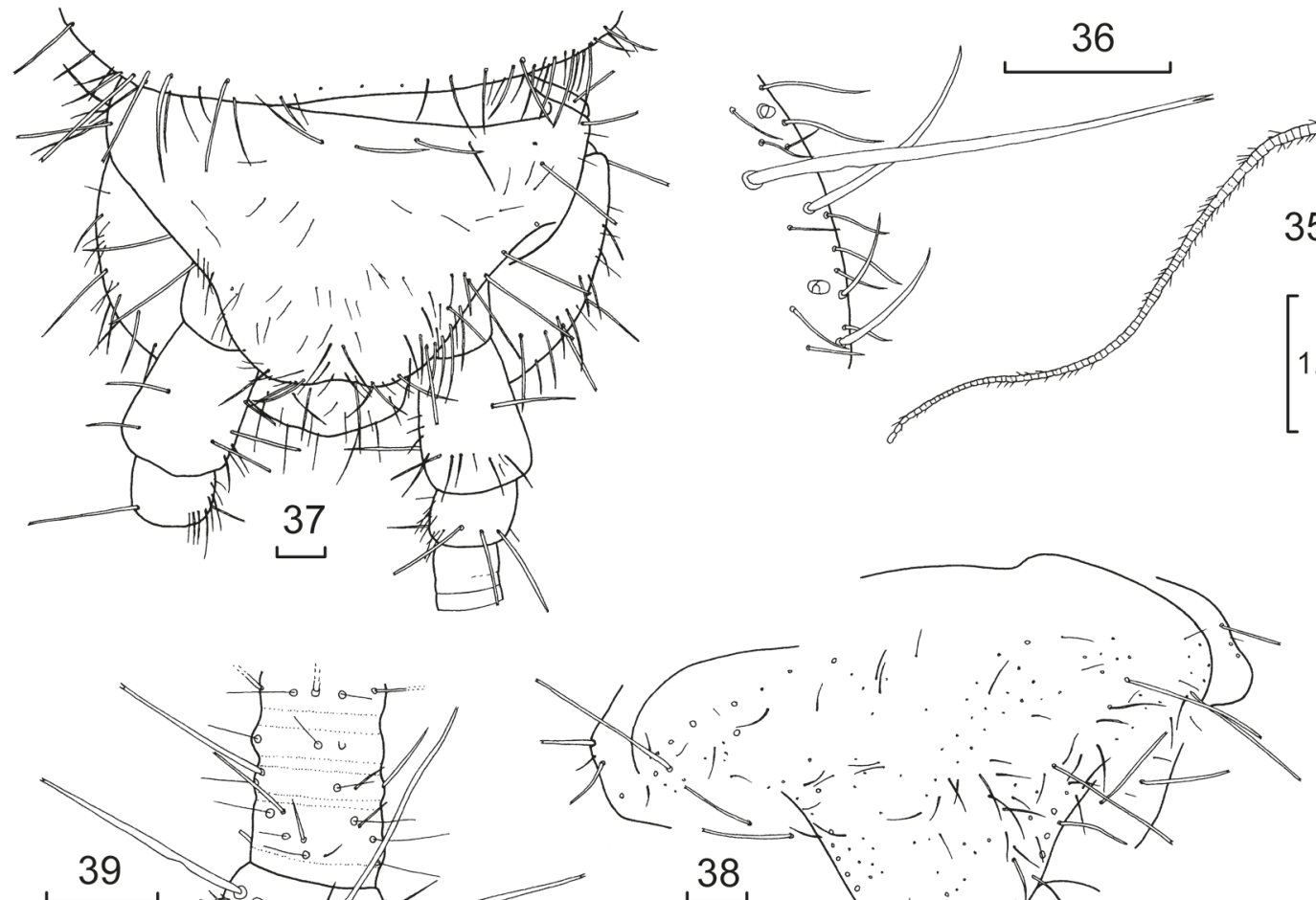

35
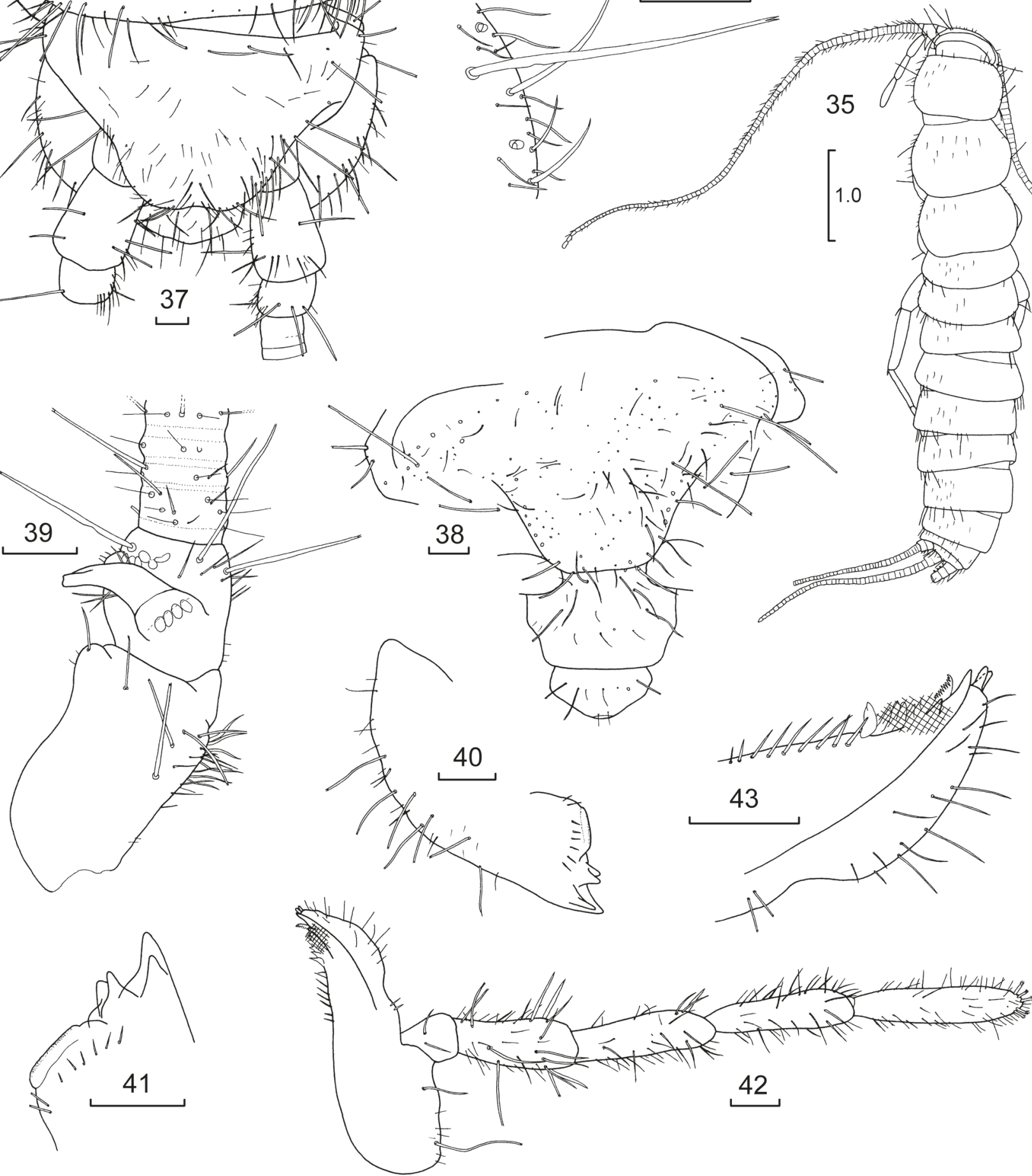

FIGURES 35-43 Metrinura taurus sp. nov., holotype §ै unless indicated otherwise by specimen number: 35, habitus; 36, macrochaeta and setae on lateral margin of pronotum; 37, head of $q$ in alcohol (E89237); 38, head, on

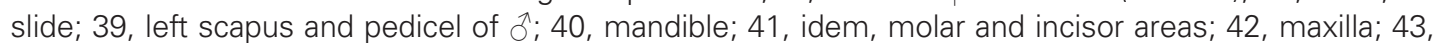
lacinia, galea and prostheca. All scale bars $0.1 \mathrm{~mm}$ unless otherwise indicated. 


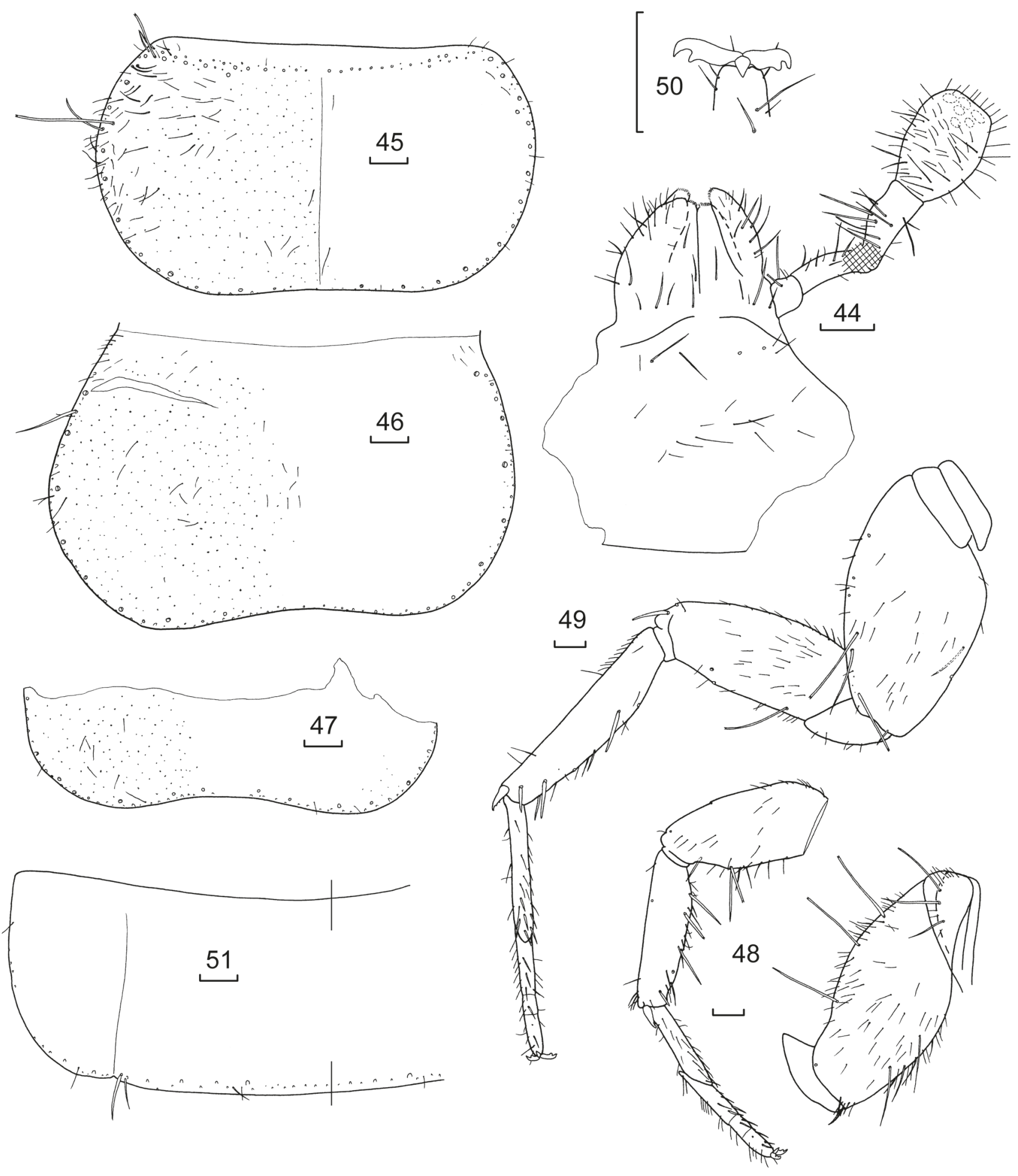

FIGURES 44-51 Metrinura taurus sp. nov., holotype ${ }^{7}$ : 44, labium; 45, pronotum; 46, mesonotum; 47, posterior half of metanotum; 48, Pl; 49, PIII; 50, pretarsus of PIII; 51, urotergite V. All scale bars $0.1 \mathrm{~mm}$. 


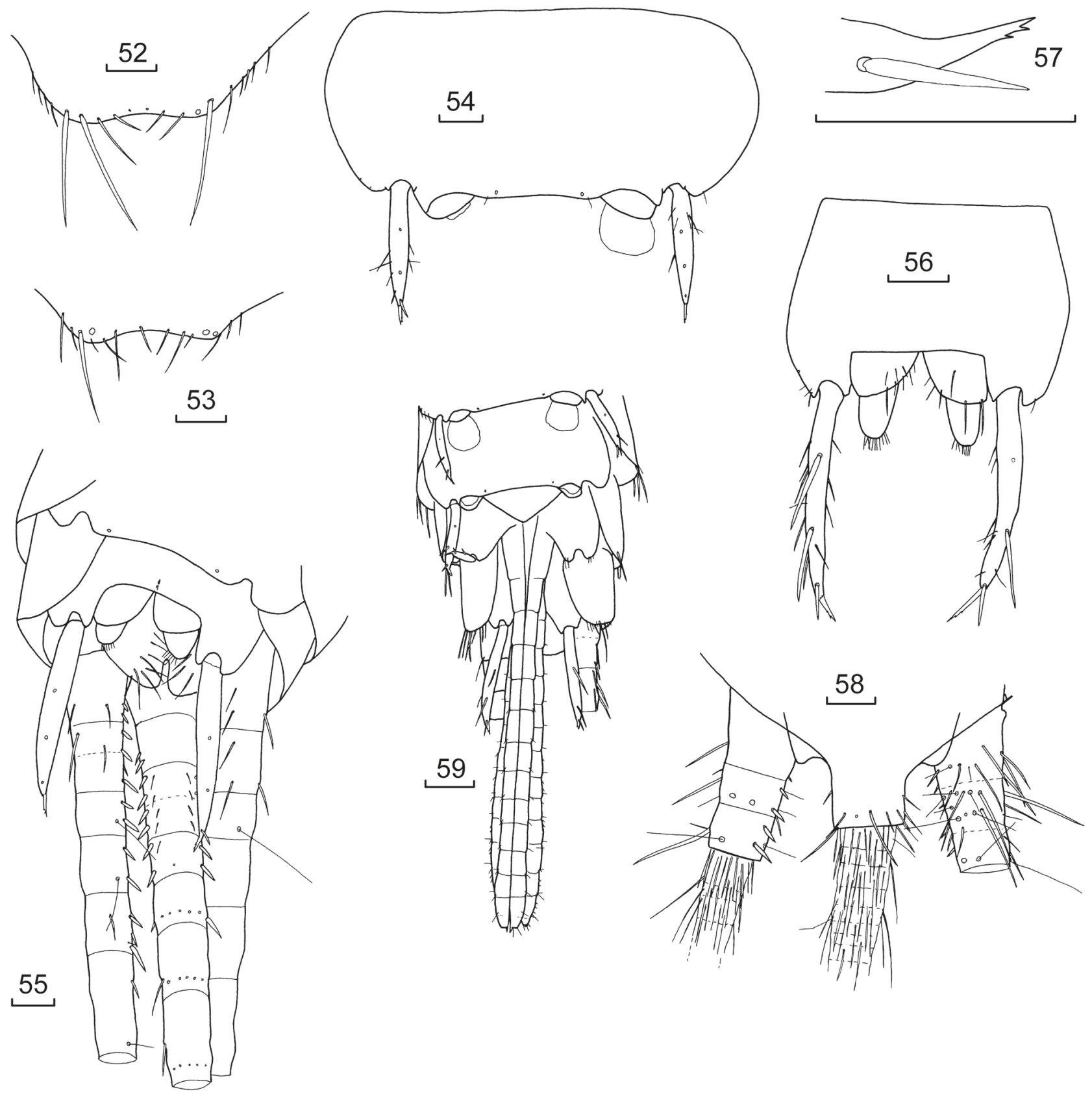

FIGURES 52-59 Metrinura taurus sp. nov., holotype ô unless indicated otherwise by specimen number: 52 , urotergite $X$

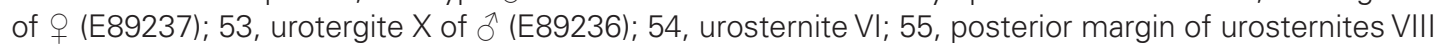
and IX, parameres, penis and base of terminal filaments of paratype (E89236), ventral view; 56, coxite IX, parameres and styli; 57 , apex of stylus IX; 58, base of terminal filaments showing protruding regrowth of terminal filaments prior to moulting; 59, urosternites VI-IX, subgenital plate and ovipositor (E89237). All scale bars $0.1 \mathrm{~mm}$. 
divisions of the cerci with two secondary modified spines also present on the sixth division (Figure 55); modified spines present on each side of the second to sixth division of the median filament. Ventro-laterally on each side of the appendix dorsalis modified setae are present as thickened spines on the second to the fifth divisions. No anemone-like structures were observed.

\section{Female}

As for male except pedicel short without apophyses; urosternite VIII divided in to separate coxites; subgenital plate subtriangular (Figure 59); ovipositor quite long, of 13-14 divisions, surpassing the apices of styli IX by about twice the length of the stylus, with short simple setae only, apical division of the anterior gonapophyses with small triangular processes. Terminal filaments lost, presumably without pegs.

\section{ETYMOLOGY}

The species is named taurus from the Latin noun for bull, referring to the 'horns' on the pedicel of the mature male.

\section{HABITAT}

All material examined was collected from boreholes in a deposit of enriched and vuggy iron ore, extending to a depth of about $25 \mathrm{~m}$ and hosted by sandstone. Mean annual rainfall at nearby Warmun weather station is 726 $\mathrm{mm}$, with $>80 \%$ of the rain falling between December and March. The mean annual maximum temperature is $35.1^{\circ} \mathrm{C}$, with mean monthly maximum temperatures being approximately $39^{\circ} \mathrm{C}$ from January to March.

\section{DISCUSSION}

The genus Metrinura now contains 10 described species, with seven from Australia (Northern Territory, Queensland and Western Australia), as well as New Caledonia and Indonesia (Celebes) and one from Colombia. Records from Papua New Guinea, Western Samoa, Vanuatu (Paclt, 1983) must be considered as unsubstantiated, due to the poor condition of the specimens but nevertheless possible (Smith, 1998). The presence of this genus in both South America and Australia implies another late Gondwanan distribution, with the Celebes species existing within the transitional zone between the Indo-Malaya and Australian biogeographic regions.

Morphological affinities are not clear. Most Australian species (M. humusa Smith, 1998, M. pedicella Smith, 1998, M. queenslandica Smith, 1998, M. russendenensis (Smith \& Shipp, 1977), M. subtropica Smith, 2006 and M. tropica Smith, 2006) as well as M. novaecaledoniae (Silvestri, 1915) from New Caledonia seem to fall within a clade, with all mature males showing an expansion of the pedicel (to a greater or lesser degree) with glandular region(s), modified chaetotaxy on all terminal filaments (stronger stout spines) and a fairly large basal division to the parameres and $2+2$ usually subequal macrochaetae on urotergite $\mathrm{X}$ and lacking anemone-like structures on the terminal filaments. M. taurus sp. nov. is quite distinct in having an extremely characteristic pointed apophysis on the pedicel of mature males and a very short basal part to the parameres, but has a similar chaetotaxy on the terminal filaments and also lacks anemone-like structures. M. taurus and M. tropica are the only species to have barbs on the outer tarsal claws. The Indonesian M. celebensis Mendes, 2002 is quite unusual in being the only species having just $1+1$ macrochaetae on urotergite $\mathrm{X}$ and with anemone-like structures on the cerci; it also has a small, but pointed apophysis on the pedicel; $M$. celebensis and M. tropica are the only known species lacking modified chaetotaxy on the median filament. Metrinura chibcha Mendes, 1997 from Colombia appears similar to the Australian group in most aspects mentioned except that the modified chaetotaxy on the terminal filaments consists of very numerous stumpy rounded pegs on pedestals rather than stout macrochaetae.

The female specimens do not give much further clarity. Most have shortish ovipositors of 7-9 divisions with only $M$. humusa and M. taurus being different, having 13-14 divisions (females of $M$. pedicella and $M$. tropica are unknown).

Smith (1998), Mendes (2002) and Smith (2006) developed a key to the species of the genus however these could now be replaced by the following with respect to the mature males:

\section{KEY TO MATURE MALES OF METRINURA MENDES}

1. Modified chaetotaxy on basal divisions of terminal filaments consisting of rounded pegs..... M. chibcha Mendes, 1997

Modified chaetotaxy on terminal filaments consisting of stout spines

2. Urotergite $X$ with $1+1$ posterior macrochaetae; with anemone-like structures as well as stout spines on the inner face of the basal divisions of each cercus M. celebensis Mendes, 2002

Urotergite $\mathrm{X}$ with $2+2$ posterior macrochaetae (sometimes the outer pair much smaller), inner face of cerci with stout spines only and always without anemone-like structures ....................... 3

3. Median filament without modified chaetotaxy........... M. tropica Smith, 2006

Median filament with stout spines along basal divisions ........................................................ 4

4. Pedicel with long curved horn-like apophysis; outer claws barbed M. taurus sp. nov.

Pedicel without horn-like apophysis, often somewhat or very swollen externally but any apophysis quite round apically; outer claws always simple ........ 5 
5. Modified chaetotaxy of median filament arranged in about four transverse rows of up to $3+3$ spines on the basal divisions ..... M. subtropica Smith, 2006

Modified chaetotaxy of median filament as longitudinal series of single stout spines on each side of the filament 6

6. Pedicel about the same length as the scape or longer.

Pedicel much shorter than scape. 9

7. Pedicel with very large prominent expansion in basal half giving the pedicel a bifurcated appearance M. pedicella Smith, 1998

Pedicel swollen more evenly, without bifurcated appearance 8

8. Swelling on pedicel more pronounced distally, modified spines on cerci quite rounded apically, posterior margin of urosternite IX quite deeply incised so that only about one third of the paramere protrudes beyond the base of stylus IX . M. queenslandica Smith, 1998

Swelling on pedicel more even so that it is widest in the middle, modified spines on cerci not obviously rounded, the parameres protruding for two thirds their length beyond the base of stylus IX M. novaecaledoniae (Silvestri, 1915)

9. Antennae more than 1.5 times $\mathrm{H}+\mathrm{B}$, legs long and thin, tarsus of PIII about 13 times longer than wide..... M. russendenensis (Smith \& Shipp, 1977)

Antennae less than $\mathrm{H}+\mathrm{B}$ length, legs stout, tarsus PIII about 8-9 times longer than wide M. humusa Smith, 1998

\section{ACKNOWLEDGEMENTS}

Specimens of the described species were collected during fieldwork undertaken on behalf of Mineralogy (Lepidospora (Brinckina) relicta) and Kimberley Metals Group (Metrinura taurus). We would also like to thank the anonymous reviewers as well as Stuart Halse of Bennelongia, for their valuable comments on the manuscript.

\section{REFERENCES}

Escherich, K. (1905). Das System der Lepismatiden. Zoologica (Stuttgart) 43: 1-164.

Halse, S.A. and Pearson, G.B. (2014). Troglofauna in the vadose zone: comparison of scraping and trapping results and sampling adequacy. Subterranean Biology 13: 17-34.

Joseph, G. (1882). Systematisches Verzeichniss der in den Tropfstein-Grotten von Krain einheimischen Arthropoden nebst Diagnosen der vom Verfasser entdechten und bisher noch nicht beschriebenen Arten. Berliner Entomologische Zeitschrift 26(1): 1-50.
Lubbock, J. (1873). Monograph of the Collembola and Thysanura. The Ray Society. London 276pp.

Mendes, L.F. (1988). Sur deux nouvelles Nicoletiidae (Zygentoma) cavernicoles de Grèce et de Turquie et remarques sur la systématique de la famille. Revue Suisse de Zoologie 95(3): 751-772.

Mendes, L.F. (1994). Evolutionary relationships among the Nicoletiidae (Insecta, Zygentoma). Acta Zoologica Fennica 195: 98-103.

Mendes, L.F. (1997). Some Zygentoma (Nicoletiidae, Ateluridae) from the Neotropics, with description of one new Metrinura species. Revue Suisse de Zoologie 104(4): 795-806.

Mendes, L.F. (2002). Some new data and descriptions of thysanurans (Zygentoma: Nicoletiidae) from Central and Eastern Africa. Annales. Musée Royal de l'Afrique Centrale. Série in Octavo. Sciences Zoologiques 290: 87-127.

Molero-Baltanás, R., Gaju-Ricart, M. \& Bach de Roca, C. (2000). On the taxonomic use of the distribution pattern of the antennal asteriform sensilla in Neoasterolepisma and Tricholepisma (Insecta, Zygentoma, Lepismatidae). Pedobiologia 44: 248-256.

Paclt, J. (1983). On some Solomon Islands, Papua New Guinea and Sarawak Thysanura. Annotationes zoologicae et botanicae, Bratislava 151: 1-10.

Remington, C.L. (1954). The suprageneric classification of the order Thysanura (Insecta). Annals of the Entomological Society of America 47: 277-286.

Silvestri, F. (1915). Thysanura della Nuova-Caledonia e delle isole Loyalty. pp. 75-81 in Sarasin, F. \& Roux, J. (eds) Nova Caledonia (A) Forschungen in Neu-Caledonien und auf den Loyalty Inseln (Recherches Scientifiques en Nouvelle Caledonie et aux Iles Loyalty 1913-1926). Volume 2. Kreideis Verlag, Wiesbaden.

Smith, G.B. (1998). Review of the Australian Nicoletiinae (Zygentoma: Nicoletiidae). Invertebrate Taxonomy 12: 135-189.

Smith, G.B. (2006). New species of Metrinura Mendes (Zygentoma: Nicoletiidae) from Queensland, Australia. Australian Journal of Entomology 45: 163-167.

Smith, G.B. (2013). A new species of Heterolepisma from Barrow Island (Zygentoma: Lepismatidae). Records of the Western Australian Museum. Supplement 83: 229-240.

Smith, G.B. (2015). New silverfish species (Zygentoma: Lepismatidae) from Barrow Island. Records of the Western Australian Museum. 30: 98-131.

Smith, G.B. (2016). New Atelurinae (Zygentoma: Nicoletiidae) from Northern Australia. General and Applied Entomology 44: $21-58$.

Smith, G.B., Eberhard, S.M., Perina, G. \& Finston, T. (2012). New species of short range endemic troglobitic silverfish (Zygentoma: Nicoletiidae) from subterranean habitats in Western Australia's semi-arid Pilbara region. Records of the Western Australian Museum 27: 101-116.

Smith, G.B. \& McRae, J.M (2014). New species of subterranean silverfish (Zygentoma: Nicoletiidae: Atelurinae) from Western Australia's semi-arid Pilbara region. Records of the Western Australian Museum. 29: 105-127.

Smith, G.B. \& Shipp, E. (1977). A new species of cave-dwelling nicoletiid silverfish (Thysanura: Insecta) from the Texas caves, Queensland. Memoirs of the Queensland Museum 19(1): 121-123.

Wygodzinsky, P. (1955). Thysanura. pp. 83-190 in B. Hanström, P. Brink \& Rudebeck, G. (eds) South African Animal Life. Vol. 2 AlmQvist \& Wiksells Boktryckeri AB, Uppsala.

MANUSCRIPT RECEIVED 4 AUGUST 2016; ACCEPTED 28 SEPTEMBER 2016. 